\title{
PENYULUHAN TENTANG PENGELOLAAN SAMPAH DAN PEMBUATAN TEMPAT SAMPAH UNIK DARI PIPA PVC UNTUK MASYARAKAT DESA SRIGADING KECAMATAN LAWANG
}

\author{
Pungky Eka Setyawan \\ Fakultas Teknik Universitas Merdeka Malang
}

\begin{abstract}
Abstrak
Pengabdian Masyarakat merupakan salah satu pilar Tri Dharma Perguruan Tinggi, disamping dharma pendidikan dan pengajaran serta dharma penelitian. Pengabdian masyarakat merupakan bagian integral tri dharma perguruan tinggi yang dalam pelaksanaannya tidak terlepas dari dua dharma yang lain serta melibatkan segenap sivitas akademik: dosen, mahasiswa, tenaga kependidikan serta alumni. Melalui pengabdian masyarakat, Unmer Malang hadir ditengah-tengah masyarakat bangsa Indonesia. Salah satu bentuk pengabdian masyarakat bagi dosen yaitu terjun di lingkungan masyarakat untuk mengaplikasikan ilmu yang ditempa selama berkecimpung didunia pendidikan perkuliahan selama menjadi tenaga pendidik. Latar belakang munculnya kegiatan pengabdian ini berawal dari kegiatan survey Di Desa Srigading Kecamatan Lawang mengidentifikasi adanya permasalahan tentang pengelolaan sampah didesa tersebut dan kurangnya kesadaran masyarakat dalam membuang sampah pada tempat sampah karena kurangnya fasilitas tempat sampah di Desa tersebut. Dengan adanya permasalahan tersebut diharapkan kegiatan pengabdian masyarakat ini dapat memberikan solusi untuk memecahkan permasalahan tentang pengolahan sampah dan pembuatan tempat sampah sebanyak 20 Pcs tempat sampah yang murah sehingga dapat memotifasi masyarakat menerapkan pola hidup bersih.
\end{abstract}

Kata Kunci : tempat sampah, pengolahan sampah, pemanfaatan sampah, inovasi bak sampah.

\section{PENDAHULUAN}

\subsection{Latar Belakang}

Dustbin atau lebih dikenal dengan sebutan tempat sampah merupakan tempat penampungan sampah sementara yang biasanya terbuat dari logam atau plastik. Di dalam ruangan, dustbin pada umumnya disimpan dalam dapur untuk membuang sisa keperluan dapur seperti kulit buah atau botol, dan ada juga tempat sampah khusus non organik yang digunakan di kantor. Beberapa tempat sampah memiliki penutup di bagian atasnya untuk menghindari keluarnya bau tidak sedap, dan kebanyakan harus dibuka manual untuk menggunakannya. Namun tong sampah saat ini sudah banyak yang menggunakan sistem pedal (tempat sampah injak), tempat sampah ini didesain agar pengguna lebih mudah dalam membuka tutup tempat sampah. Tempat umum seperti taman pada saat ini banyak terdapat tong sampah yang ditempatkan di sisi sepanjang jalan yang secara frekuentif dapat dijumpai tiap jalan, hal ini untuk menghindari kebiasaan membuang sampah sembarangan yang dapat mengganggu keindahan serta kesehatan lingkungan.

Akan tetapi karena harga dari dustbin yang relative mahal membuat masyarakat enggan membeli akibatnya, dampak negative dari kurang maksimalnya penggunaan dustbin yaitu sampah ditumpuk dan dibuang ditempat- tempat tertentu sehingga menimbulkan bau yang tidak sedap serta terganggunya pemandangan akibat sampah yang menumpuk. Sebagaian besar warga desa diwilayah lawang ini mata pencahariannya petani dan buruh yang pendapatan mereka pas-pasan. Mereka berpikir dua kali untuk membeli tempat sampah / dustbin karena harga yang relative mahal. Untuk itu dibutuhkan solusi untuk memecahkan masalah sampah di wilayah lawang tersebut dengan memberikan penyuluhan tentang dampak negative sampah beserta solusi pemecahannnya. Dan saya selaku dosen fakultas teknik jurusan teknik mesin akan membagikan ilmu saya untuk memecahkan permasalahan sampah di Desa Srigading Lawang dan akan membantu masyarakat dengan membuat tempat sampah yang murah dan unik yang terbuat dari pipa PVC 20 Pcs tempat 
sampah, sebagai motivasi untuk warga desa Srigading Kecamatan Lawang agar mudah dalam membuang sampah.

\subsection{Perumusan Masalah}

Permasalahan yang ada di Desa Srigading Kecamatan Lawang yaitu :

1. Bagaimanakah cara pengolahan sampah di Desa Srigading Kecamatan Lawang ?

2. Bagaimanakah cara membuat tempat sampah yang murah dan efektif dari pipa PVC di Desa Srigading Kecamatan Lawang?

\subsection{Tujuan}

1. Lingkungan di sekitar Desa Srigading Kecamatan Lawang dapat tetap terjaga kebersihanya.

2. Meningkatkan kesadaran para masyarakat disekitar akan pentingnya suatu lingkungan yang bersih.

\subsection{Target}

Setelah adanya penyuluhan tentang pengelolaan sampah dengan memberikan pemahaman dan kesadaran kepada masyarakat tentang pentingnya mengolah sampah, diharapkan dapat mencapai target yang diinginkan. Target yang diinginkan yaitu:

1. Meningkatkan kepedulian masyarakat di Desa Srigading Kecamatan Lawang terhadap kebersihan dengan tidak membuang sampah sembarangan dan tidak membuang sampah disungai.

2. Masyarakat Desa Srigading Kecamatan Lawang dapat melakukan pengolahan sampahsecara mandiri.

3. Dapat membuat tempat sampah dari pipa PVC yang murah dan efektif sehingga lingkungan menjadi Asri, bersih, sehat

\subsection{Luaran}

Dengan adanya penyuluhan dan sosialisasi tentang Pengolahan Sampah dan pembuatan tempat sampah unik dari pipa PVC kepada masyarakat Desa Srigading Kecamatan Lawang maka luaran yang diharapkan yaitu:

1. Memberikan pengetahuan kepada masyarakat mengenai pentingnya membuang sampah di tempat sampah.

2. Memberikan pengetahuan kepada masyarakat tentang cara pembuatan tempat sampah dari pipa PVC yang mudah praktis dan ekonomis.

3. Memberikan pengetahuan kepada masyarakat mengenai pentingnya pengolahan sampah untuk menciptakan lingkungan yang sehat.

\section{METODE KEGIATAN}

\section{Metode Pendekatan Program}

1. Implementasi penyuluhan dan sosialisasi tentang pembuangan sampah di tempat sampah.

2. Implementasi penyuluhan dan sosialisasi tentang dampak negative sampah yang dibuang di sembarang tempat.

3. Implementasi cara pembuatan tempat sampah yang praktis dan ekonomis dari pipa PVC.

4. Implementasi penyuluhan tentang pengolahan sampah.

\section{Prosedur Realisasi Program}

Pada tahap persiapan penyuluhan, yang dilakukan adalah penentuan lokasi, pengenalan lingkungan sekitar yang bertujuan untuk menghimpun data desa berupa kondisi fisik, sosial dan lingkungan sekitar. Kemudian dilanjutkan dengan melakukan pengenalan dan penentuan peserta program.

Pada tahap pelaksanaan kegiatan penyuluhan dan pembuatan tempat sampah dari bahan pipa PVC. Sebelumnya dilakukan persiapan materi penyuluhan, persiapan sarana dan prasarana kegiatan penyuluhan dan kemudian dilanjutkaan dengan pelaksanaan program.

Pada tahap akhir akan dilakukan evaluasi. Evalusi ini bertujuan untuk melihat perkembangan dan kemajuan program yang dilaksanakan, sekaligus untuk mengetahui kendala dan penyelesaian sehingga program ini dapat benar-benar efektif dan maksimal serta berguna bagi masyarakat. Kemudian akan diketahui pula adanya pertambahan pengetahuan dan kesadaran masyarakattentang pentingnya pengelolaan sampah yang baik untuk menciptakan lingkungan yang bersih, asri dan terhindar dari polusi sampah dan banjir. Masyarakat mampu membuat tempatsampah dari bahan pipa PVC secara mandiri yang ekonomis dan praktis sehingga dapat meningkatkan kebersihan dilingkungan Desa Srigading Kecamatan Lawang.

Pembuatan Tempat Sampah dari Pipa PVC 
Pembuatan tempat sampah dari bahan pipaPVCyang ramah lingkungandan murah meriahyaitu sebagai berikut:

\section{Bahan}

1. PipaPVC $3 / 4$ inch

2. 8 elbow pipaPVC $3 / 4$ inch

3. $4 \mathrm{~T}$ pipaPVC $3 / 4$ inch

4. Amplas (grade 200 dan grade 600)

5. Lem pipa paralo
Alat
1. Gergaji besi
2. Spidol
3. Penggaris

\section{Prosedur Pembuatan Tempat sampah dari}

1. Menyiapkan bahan-bahan untuk membuat tempat sampah pipaPVC

2. Menyiapkan alat-alat untuk membuat tempat sampah pipaPVC.

3. Memotong pipa PVC menjadi 3 bagian diantaranya
a. $26 \mathrm{~cm}$ sebanyak 2 buah untuk tinggi tempat sampah.
b. $10 \mathrm{~cm}$ sebanyak 8 buah untuk sisi yang disambungkan dengan pipa $\mathrm{T}$.
c. $25 \mathrm{~cm}$ sebanyak 4 buah untuk sisi yang disambungkan dengan elbow.

4. Setelah pipa PVC dipotong sesuai kuran selanjutnya pipa PVC ukuran $25 \mathrm{~cm}$ sebanyak 4 buah disambungkan dengan 8 elbow di masing-masing sisi. Selanjutnya, pipa PVCdengan ukuran $10 \mathrm{~cm}$ sebanyak 8 buah disambungkan pada sisi kanan dan kiri pada setiap pipa $\mathrm{T}$.

5. Kemudian pipaPVCukuran $25 \mathrm{~cm}$ yang sudah disambungkan dengan elbow selanjutnya disambungkan dengan pipa PVC ukuran $10 \mathrm{~cm}$ yang sudah disambungkan dengan pipa $T$.

6. Selanjutnya disambungkan dengan pipa PVCukuran $26 \mathrm{~cm}$ pada bagian bawah pipa T.

7. Tempat sampah yang dibuat sebanyak 25 Pcs, hasilnya dapat dilihat seperti pada Gambar 1

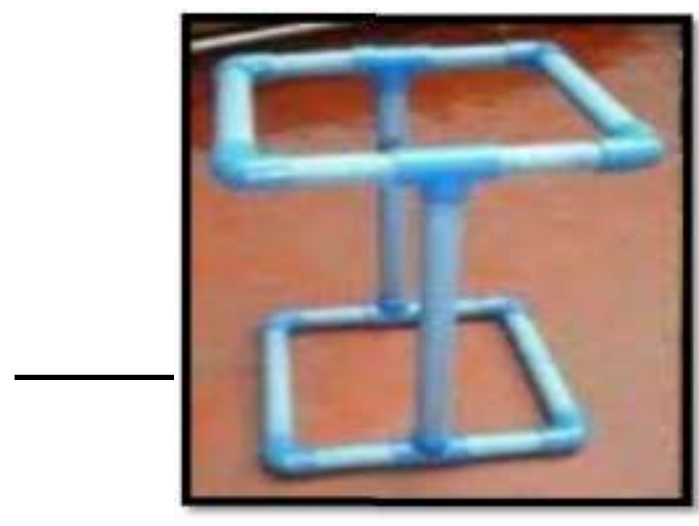

Gbr 1. Desain Unik Tempat Sampah dari pipa PVC

\section{Anggaran Biaya}

Anggaran biaya yang diajukan untuk kegiatan Pengabdian Kepada Masyarakat ditunjukkan di Tabel 5.1.

Tabel 5.1 Format Ringkasan Anggaran Biaya yang Digunakan

\begin{tabular}{|c|l|r|}
\hline No & \multicolumn{1}{|c|}{ Komponen } & $\begin{array}{r}\text { Biaya yang diusulkan } \\
\text { (Rp) }\end{array}$ \\
\hline 1 & Narasumber & 250.000 \\
\hline 2 & $\begin{array}{l}\text { Biaya pelaksanaan dan } \\
\text { peralatan penunjang }\end{array}$ & 550.000 \\
\hline 3 & $\begin{array}{l}\text { Biaya bahan habis } \\
\text { pakai }\end{array}$ & 1.200 .000 \\
\hline 4 & Biaya perjalanan & 400.000 \\
\hline 5 & biaya lain-lain & 100.000 \\
\hline \multicolumn{2}{|c|}{ Jumlah } & $\mathbf{2 . 5 0 0 . 0 0 0}$ \\
\hline
\end{tabular}

\section{Jadwal Program}

Adapun jadwal pelaksanaan program adalah ditunjukkan pada Tabel 5.2.

Tabel 5.2 Jadwal Pelaksanaan Program

\begin{tabular}{|c|c|c|c|c|c|}
\hline \multirow{2}{*}{ No, } & \multirow{2}{*}{ Kegratan } & \multicolumn{4}{|c|}{ Mirgera } \\
\hline & & 1 & 2 & 3 & 4 \\
\hline 1 & Persiapan kegiasan & & & & \\
\hline 2 & Sosialisei prog ana peapulatua & & & & \\
\hline 3 & Penyulathan tentang kebarihas demipak asgative sampath & & & & \\
\hline 4 & Penyulahan dan sosialisesi tentare penqo:ahan sanpah & & & & \\
\hline 5 & Pemburtan tempat sampla dari pipa PVC sebanyac $25 \mathrm{PCs}$ & & & & \\
\hline 6 & Monitoring dan evaluasi & & & & \\
\hline 7 & Memboar laporan & & & & \\
\hline
\end{tabular}

\section{HASIL DAN PEMBAHASAN}

Identifikasi Sampah Di Desa Srigading Kecamatan Lawang

Masalah sampah adalah masalah semua orang, termasuk di Desa Srigading Kecamatan Lawang. Kondisi ini mendorong kami sebagai Peneliti dan Staf Pengajar/ Dosen Teknik Mesin Unmer Malang memberikan solusi dalam mengelola sampah warga di Desa Srigading Kecamatan Lawang. Mengelola sampah sebenarnya tidak terlalu sulit, yang lebih sulit adalah memberikan pemahaman kepada warga untuk mengelola sampah 
dan menjalankan program ini. Karena selama ini belum ada solusi yang jitu untuk menangani masalah sampah di Desa Srigading Kecamatan Lawang maka kami menawarkan solusi dalam pengelolaan sampah rumah tangga di Desa tersebut.

\section{Karakteristik Sampah Warga}

Sampah warga sama seperti sampah-sampah kota pada umumnya. Sampah ini bercampur antara sampah organik dengan sampah non organik. Warga membutuhkan penyuluhan dari perangkat desa untuk memisahkan antara sampah organik dengan sampah non organik. Sampah-sampah ini dikumpulkan setiap dua hari sekali oleh petugas sampah.Sampah non organik yang paling banyak adalah sampah plastik. Jenis sampah di Desa Srigading Kecamatan Lawang ada dua jenis yaitusampah non organik dan sampah organik. Dari setiap kelompok ini berdasarkan bisa tidaknya didaur ulang dapat dikelompokkan menjadi bisa didaur ulang dan tidak bisa didaur ulang.

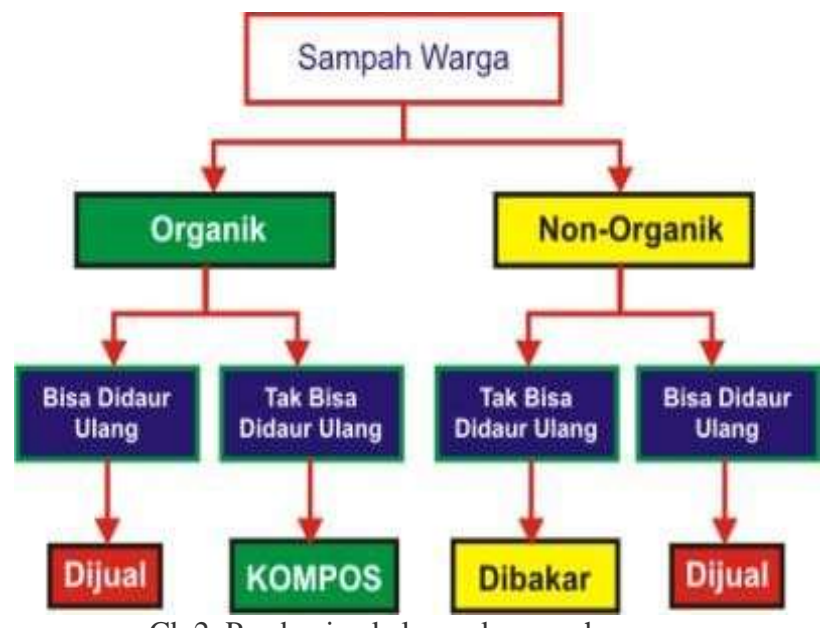

Gb 2. Pembagian kelompok sampah warga

Contoh kelompok sampah tersebut adalah sebagai berikut:

a. Sampah Organik Bisa Didaur Ulang : kertas, kardus, koran, majalah, dll

b. Sampah Organik Tak Bisa Didaur Ulang: sisa makanan, daun, sisa sayuran, dll.

c. Sampah Non-organik Bisa Didaur Ulang: logam (besi, alumunium, tembaga), botol, bekas botol minuman, kaleng, plastik, kaca, dll.

d. Sampah Non-organik Tak Bisa Didaur Ulang: plastik yang tidak bisa diaur ulang, baterai bekas, dll.
Sampah-sampah yang bisa didaur ulang baik organik maupun non-organik bisa dijual. Sedangkan sampah non-organik yang tidak bisa didaur ulang seharusnya dibakar. Namun, saat ini mereka belum memiliki incinerator untuk membakar sampah. Jika sampah ini dibakar langsung akan diprotes warga, karena asapnya ke mana-mana dan masuk ke rumah-rumah warga. Dengan incinerator, cerobong bisa dibuat tinggi sehingga asap bisa langsung ke udara. Selain itu pembakaran bisa berlangsung sempurna dan mengurangi pencemaran udara .Sampah organik diolah menjadi kompos. Kompos dapat diolah lagi menjadi pupuk organik untuk dijual. Atau digunakan sendiri untuk menanam tanaman hias, tanaman apotik hidup, atau tanaman sayuran/buahbuahan.

\section{Proses Pengelolaan Sampah}

Proses pengolahan sampah warga kurang lebih sebagai barikut :

\section{Pengumpulan Sampah Warga}

Sampah warga dikumpulkan dari rumah ke rumah yang seluruhnya terdiri dari beberapa RT misalnya. Sampah ini dikumpulkan oleh petugas yang khusus setiap 2 hari sekali dengan menggunakan gerobak sampah. Sampah-sampah ini dikumpulkan di tempat penampungan sementara. Petugas yang terdiri dari dua orang bekerja dari pagi sampah menjelang sholat dhuhur.

\section{Sortasi Sampah}

Di tempat penampungan sampah, sampah-sampah ini disortasi. Ada dua petugas lagi yang bekerja untuk melakukan sortasi sampah ini. Sampahsampah yang bisa didaur ulang dikumpulkan dan dibersihkan dari sampah yang lain. Sampah-sampah non- organik yang tidak bisa didaur ulang juga dipisahkan tersendiri. Sedangkan sampah organik yang tidak bisa didaur ulang dipisahkan untuk diolah menjadi kompos. Ada beberapa sampah organik yang tidak ikut dikomposkan, yaitu: kayu, bambu, tulang, dan tanduk. Sampah-sampah ini bisa dikomposkan tetapi membutuhkan waktu yang lebih lama, sehingga tidak sesuai jika dicampurkan dengan sampah organik yang lain. Selain itu jumlah sampah ini tidak terlalu banyak.

Sortasi sampah merupakan bagian yang cukup rumit. Banyak makan waktu dan tenaga. Para pengelola sampah di Desa Srigading Kecamatan Lawang harus rajin mengajak warga memisahkan sampah organik dan non organik sejak 
dari rumah-rumah. Hal ini perlu penyadaran yang terus menerus, mungkin perlu waktu lama tetapi harus dimulai sejak dari sekarang. Mungkin sebagai perangsang bisa dengan memberikan reward bagi warga yang mau memisahkan sampahnya. Rewardnya tidak perlu mahal- mahal, misalnya warga yang mau memisahkan sampahnya diberi hadiah tanaman hias atau tanamantanaman yang lain.

\section{Pengomposan}

Sampah-sampah organik yang tidak bisa didaur ulang diolah menjadi kompos dengan menggunakan aktivator PROMI. Sebelumnya mereka pernah mencoba menggunakan aktivatoraktivator lain yang banyak dijual di toko pertanian. Namun, karena prosesnya agak 'ribet' dan membutuhkan banyak bahan tambahan, seperti: gula, kapur, pupuk kandang, dll mereka lebih memilih PROMI. PROMI tidak membutuhkan bahan tambahan, tidak memerlukan pencacahan, dan tanpa pembalikan. Hanya saja PROMI belum tersedia di pasaran luas.PROMI adalah formula mikroba unggul yang mengandung mikroba pemacu pertumbuhan tanaman, pelarut hara terikat tanah, pengendali penyakit tanaman, dan dapat menguraikan limbah organik pertanian/ perkebunan. Bahan aktif Promi adalah mikroba unggul asli Indonesia yang telah diseleksi dan diuji di Balai Penelitian Bioteknologi Perkebunan, Bogor, yaitu Trichoderma harzianum DT 38, T. pseudokoningii DT 39 dan Aspergillus sp.

\section{Pengelolaan sampah rumah tangga}

Proses pengomposan sampah warga dengan menggunakan PROMI dilakukan dengan cara sebagai berikut:

\section{a. Penyiapan PROMI}

Karena umunya sampah warga mengandung kadar air cukup tinggi, maka PROMI tidak diencerkan dengan air. Pengenceran PROMI menggunakan tanah kering atau kompos yang telah jadi. JIka kadar air kurang maka ditambahkan sedikit air.

\section{b. Penyiapan Tempat Pengomposan}

Tempat pengomposan dibuat dengan menggunakan pagar bambu. Di sekeliling pagar ini diberi lapisan plastik untuk menjaga suhu dan kelembaban. Plastik yang digunakan adalah plastik bekas. Bagian bawah/dasar tidak dilapisi plastik.

\section{c. Penyiapan Sampah}

Sampah organik dimasukkan ke dalam bak kompos selapis dengan tinggi kurang lebih 10 $\mathrm{cm}$. PROMI yang telah diencerkan ditaburkan di atas sampah ini. Selanjutnya tumpukan sampah diinjak- injak agar sedikit memadat. Proses ini dilakukan berulang-ulang hingga bak penuh.

\section{d. Penutupan dengan Plastik}

Jika seluruh sampah organik pada hari itu telah selesai dimasukkan ke dalam bak kompos. Selanjutnya tumpukan kompos tersebut ditutup dengan plastik. Penutupan harus rapat untuk menjaga suhu dan kelembaban. Jika bak belum penuh, maka esok hari ditabahkan sampan organik lagi dengan cara yang sama hingga bak penuh.

\section{Pemanfaatan Kompos/Pupuk Organik}

Setelah jadi kompos kira-kira dalam waktu 2-4 minggu, kompos tersebut dapat langsung digunakan. Kompos dapat juga dibuat menjadi pupuk organik. Pertama, kompos dikeringkan di bawah sinar matahari. Selanjutnya kompos diayak. Kompos yang halus dikemas dalam kantong plastik. Kompos ini bisa diual dengan harga cukup lumayan.Jika akan digunakan sendiri, kompos tidak perlu diolah lebih lanjut. Lansung digunakan saja. Kompos ini dapat digunakan untuk menanam bermacam-macam tanaman. Misalnya saja tanaman hias. Banyak tanaman hias yang bisa ditanam dengan kompos ini. Alternatif lain adalah menanam tanaman sayuran, bisa tomat, bayam, caisim, kangkung. Atau tanaman buah-buahan, seperti buah pepaya atau pisang yang waktu berbuahnya tidak terlalu lama. Kompos juga bisa digunakan untuk menanam tanaman obat/apotik hidup.Tanaman ini bisa saja dijual atau disumbangkan untuk warga disekitar lokasi pengelolaan kompos.

\section{KESIMPULAN}

1. Untuk mengelola sampah ini dibutuhkan partisipasi warga secara musyawarah. Pengelolaan sampah mungkin bisa dimulai dengan membentuk kelompok kecil. Pengelola ini dketuai oleh Pak RW misalnya, seorang bendahara dan beberapa pekerja (saat ini berjumlah 4 orang). 
2. Warga ditarik iuran per rumah. Uang hasil iuran ini digunakan untuk membayar petugas pengelola, khususnya pekerja.

3. Pekerja diambil dari warga setempat yang masih mengganggur. Jadi secara tidak langsung pengelolaan sampah ini juga membuka lapangan kerja bagi warga yang belum bekerja.

4. Setiap hari pekerjaan dibagi menjadi dua shift: shift pagi mulai dari jam $8-12$ dan shift siang mulai dari jam 12 sampai jam 16. Setiap shift dua orang yang bekerja. Pekerja shift pagi bertugas untuk mengambil sampah dari rumah-rumah warga. Petugas shift kedua bertugas untuk memilih-milih sampah, mana sampah yang bisa didaur ulang dan mana sampah yang akan dikomposkan.

5. Pekerja bekerja sehari libur sehari masuk, jadi hari kerjanya 15 hari kerja. Misalnya, Satu shift setiap pekerja diberi upah Rp.
10.000. tidak terlalu besar tetapi cukup lumayan untuk mereka.

6. Pembuatan tempat sampah dari pipa PVC sangat mudah dan praktis. Warga bisa membuat sendiri.

7. Tempat sampah dari pipa PVClumayan awet dan tahan terhadap cuaca dibandingkan dengan tempat sampah konvensiaonal dari bahan kayu dan plastik yang relatif mudah rusak ketika terkena cuaca panas dan hujan.

\section{DAFTAR PUSTAKA}

1. Callister, Willam D. 2007. Material Science and Engineering : An Iintroduction. John Willey \& Sons. Singapore.

2. Prodiindustri. "Perancangan dan pengembangan Desain Produk Tespen. "Http:// prodiindustri.wordpress.com/ perencanan-dan-pengembangan-produk/. 